\title{
磁场与血管生成研究进展
}

朱一鸣 ${ }^{1,2 \dagger}$, 方彦雯 ${ }^{3 \dagger}$, 杨建成 ${ }^{4,5}$, 纪新苗 ${ }^{2}$, 方志财 ${ }^{3}$, 商澎 $^{4^{*}}$, 张欣 ${ }^{1,2^{*}}$

1. 安徽大学物质科学与信息技术研究院, 合肥 230601 ;

2. 中国科学院合肥物质科学研究院, 强磁场科学中心, 合肥 230031 ;

3. 和也健康科技有限公司, 湖州 313300;

4. 西北工业大学深圳研究院, 深圳 518057;

5. 南方医科大学附属深圳市龙华区人民医院脊柱外科, 深圳 518109

$\dagger$ 同等贡献

* 联系人, E-mail: shangpeng@nwpu.edu.cn; xinzhang@hmfl.ac.cn

2019-12-18 收稿, 2020-01-27 修回, 2020-01-29 接受, 2020-02-13 网络版发表

国家自然科学基金(U1532151)资助

摘要 血管生成参与了多种生理和病理过程, 是器官生长和修复的关键, 在外科中起着至关重要的作用. 目前已有 大量关于磁场对血管生成影响的研究报道. 本文对现有数据进行总结、分析和比较, 包括不同磁场类型、磁场参 数、处理方式、处理对象和磁场处理导致的血管生成变化等. 由于针对不同磁场参数的系统性研究相对缺乏, 目 前细胞水平上的研究结果尚无确切的规律. 然而动物水平上的研究结果显示, 肿瘤组织的血管生成可以被多种磁 场所抑制, 而长时间或者较高磁场强度的稳态磁场处理非肿瘤组织似乎有促进血管生成的趋势, 对此人们还需要 进行更系统的研究来进一步确认. 此外, 本文还讨论了磁场与化疗等其他治疗方法联合使用对血管生成的影响, 并 总结分析磁场影响血管生成的潜在机制. 这不仅有助于人们进一步了解磁场生物学效应, 为磁外科技术的安全应 用提供实验基础，而且可能为未来将磁场在医学领域的其他潜在应用奠定基础.

关键词 稳态磁场, 动态磁场, 血管生成, 磁场强度, 肿瘤

磁场主要可以分为稳态磁场和动态磁场. 稳态磁 场是指在一定时间和空间内磁场强度和方向不随时间 而变化的磁场，其可根据磁感应强度的不同分为弱磁 场 $(<1 \mathrm{mT})$ 、中等磁场 $(1 \mathrm{mT} \sim 1 \mathrm{~T})$ 、强磁场 $(1 \sim 20 \mathrm{~T})$ 和 超强磁场 $(\geqslant 20 \mathrm{~T})^{[1,2]}$. 稳态磁场的磁场参数相对较少, 有利于进行磁场生物学效应的基础研究 ${ }^{[3 \sim 9]}$. 动态磁场 是指强度和方向随时间变化的磁场, 其分类复杂, 不仅 存在场强和空间分布的变化情况，还有各种频率、波 形等变化.

血管形成的模式主要有血管发生(vasculogenesis)、血管生成(angiogenesis)和动脉生成(arteriogenesis), 这三者在发生部位、诱发和调节因素等方面有一
定区别和联系．血管发生是指肧胎发育时成血管细胞 分化为内皮细胞，内皮细胞进而组装成初级血管丛的 过程. 初级血管丛形成后所产生的更多的内皮细胞通 过发芽或从原来的血管分支形成新的毛细血管的过程 被称为血管生成. 然后发生动脉生成, 即内皮细胞通道 被周细胞或血管平滑肌细胞覆盖，从而提供稳定性和 控制灌注 ${ }^{[10,11]}$. 由于有关磁场与血管发生/动脉生成的 研究非常缺乏, 本文中我们主要讨论磁场与血管生成.

\section{1 磁场对血管生成的影响}

血管生成包含并参与了多个生理和病理过程. 血 管在进化过程中出现, 从而允许造血细胞在机体内巡 
逻, 进行免疫监视, 提供氧气和营养, 并去除代谢产物, 不仅滋养着机体几乎每一个器官，同时还以灌注无关 的方式为组织器官的生成和维护传递指示信号 ${ }^{[10]}$. 然 而, 血管对组织生长和再生有益的同时, 血管生成的失 调会导致许多疾病. 例如, 血管过度生长或异常重塑会 导致癌症、炎性疾病和眼病等 ${ }^{[12,13]}$ ，而血管生长不足 和血管异常退化不仅会导致心、脑缺血, 还会导致神 经退行性病变、高血压、呼吸莬迫和骨质疏松等疾 病 $^{[12,13]}$. 因此，血管生成是近年来多领域的一个研究热 点. 本文对磁场与血管生成的研究进展进行归纳总结, 并对造成实验结果相互冲突或包容的可能因素进行分 析，不仅为磁外科中磁场对组织中血管生成的影响提 供借鉴, 也为未来磁场在其他相关生物医学领域的应 用开发提供参考.

\section{1 稳态磁场与血管生成}

磁外科中主要运用的是稳态磁场, 通过磁体间特 殊的“非接触性”磁场力对人体组织, 如肠管、血管、 骨性组织等进行吻合、汼拉、排斥、导航等. 磁外科 技术已被用于胃肠道吻合、食管闭锁(狭窄)再通、胆 道闭锁(狭窄)再通、胆肠吻合、血管吻合、直肠阴道 瘘修补等众多领域中, 可极大地简化现有手术操作过 程、降低操作难度、缩短操作时间、提高治疗效果, 并对一些临床疾病的治疗模式和观念产生了颠覆性的 改变 ${ }^{[14]}$. 磁外科与血管生成关系密切. 例如, 磁压榨技 术利用磁体之间“非接触性”磁场力使压迫吻合部位组 织发生缺血——坏死一一脱落, 而压榨旁组织发生粘 连一修复——愈合的病理变化过程, 从而实现器官
吻合 ${ }^{[15]}$, 这一系列过程都需要血管生成的参与. 因此, 了解磁场与血管生成的关系可以在一定程度上明确磁 外科技术的临床安全性和可靠性，推进磁外科技术的 进步.

目前已有多项研究表明, 不同参数的稳态磁场可 以影响血管生成.

一些研究表明, 稳态磁场能够抑制血管生成. 例如, 2008年, Strieth等人 ${ }^{[16]}$ 研究发现携带A-Mel-3肿瘤的仓 鼠暴露于587 $\mathrm{mT}$ 的稳态磁场 $3 \mathrm{~h}$ 后肿瘤的功能血管密 度可逆性降低，提示稳态磁场对肿瘤血管生成可能有 抑制作用. 2009年, Strelczyk等人 ${ }^{[17]}$ 研究了长时间暴露 于稳态磁场对肿瘤血管生成和生长的影响, 结果发现 $586 \mathrm{mT}$ 稳态磁场处理 $3 \mathrm{~h}$ 后, 功能性血管的密度、直径 以及红细胞流速显著降低，表明磁场处理肿瘤可能抑 制血管生成从而延缓血管成熟. 随后, 2014年, Gellrich 等人 ${ }^{[18]}$ 研究发现 $587 \mathrm{mT}$ 稳态磁场处理可显著减少异硫 氧酸苂光素(fluorescein isothiocyanate, FITC)-葡聚糖 (dextran)标记的功能性肿瘤微血管, 而且反复曝磁组的 微血管渗漏更明显(图1). 此外, 2009年, 商澎课题组 ${ }^{[19]}$ 也报道了 $0.2 \sim 0.4$ T的梯度稳态磁场可以抑制血管生成. 他们观察到磁场处理 $24 \mathrm{~h}$ 后人脐静脉内皮细胞(human umbilical veins endothelial cells, HUVECs)的增殖能力 受到显著抑制, 并且发现连续暴露于梯度稳态磁场的 鸡胚线毛尿囊膜(chick chorioallantoic membrane, $\mathrm{CAM}$ )中的血管数量均少于正常情况下的血管数量, 磁 场处理7 9 d的CAM中血红蛋白的含量也较少. 同时, 基质胶小室模型中的血管密度和血红蛋白含量的结果 也表明暴露梯度稳态磁场 7 或 $11 \mathrm{~d}$ 抑制了血管生成. 然
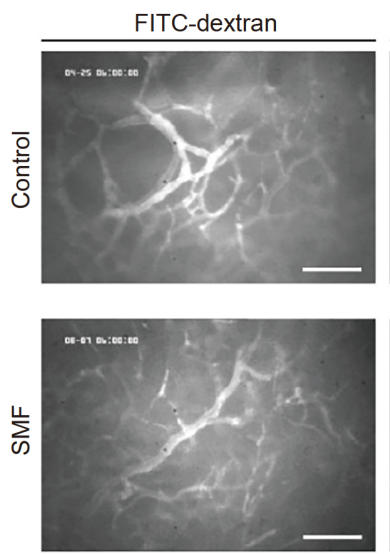

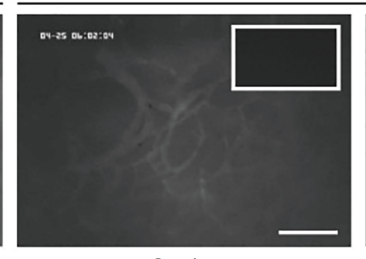

$2 \mathrm{~min}$

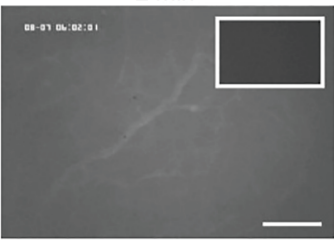

Rhodamine-albumin

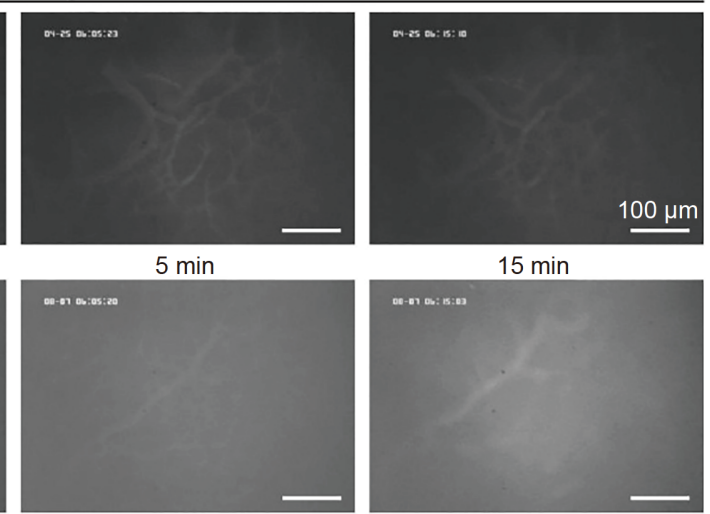

图 $1587 \mathrm{mT}$ 反复曝磁导致携带A-Mel-3肿瘤的仓鼠体内肿瘤微血管密度降低和渗漏增加. 摘自文献[18]

Figure 1 Repeated $587 \mathrm{mT}$ static magnetic field (SMF) treatments resulted in increased leakage and decreased microvascular density in the A-Mel-3 tumors in hamsters. Image was adapted from Ref. [18] 
而, 2018年, Gellrich等人 ${ }^{[20]}$ 研究发现, 虽然与 $587 \mathrm{mT}$ 稳 态磁场每日 $35 \mathrm{~min}$ 处理组 $(3 \sim 11 \mathrm{~d})$ 相比, 稳态磁场暴露 $2 \mathrm{~h}(3,6,9 \mathrm{~d})$ 可显著降低携带LLC-1肿瘤小鼠的肿瘤生 长, 但其功能性血管密度并无显著降低.

但是, 还有一些研究结果显示, 稳态磁场能够促进 血管生成. 例如, 1994年, Balyasnikova等人 ${ }^{[21]}$ 报道 140 $\mathrm{mT}$ 稳态磁场加速了牛肺动脉内皮细胞的生长速度, 而 且显著加速了HUVECs的分化(体外血管生成), 但对人 脐静脉内皮细胞的附着和生长没有影响. 我国研究者 应用稳态磁场治疗 25 例慢性小腿溃疡, 将0.06 0.08 T 的锶铁氧体磁片的 $\mathrm{N}$ 极紧贴患者创面, 通过治疗前后的 组织病理观察发现稳态磁场疗法能够促进毛细血管增 生、扩张及充血, 改善局部循环, 从而加速溃疡愈合 ${ }^{[22]}$. 2006年，Xu等人 ${ }^{[23]}$ 采用微球注射方法研究局部稳态磁 场暴露对缺血骨侧支血管形成的影响, 将钐钴磁化棒 植人大鼠缺血股骨骨干中段，发现与非磁棒植人骨的 实验组相比，暴露于稳态磁场近端区域的缺血骨的骨 密度和微球数明显增加, 而微球数量的增加似乎是由 于缺血骨中形成了较小的侧支血管.

关于稳态磁场在整体或者组织水平上影响血管生 成的研究总结见表 1 .

从目前的研究结果来看(表1), 由于不同实验中所 使用的磁场强度、处理时间和生物样品类型的差异等 多种因素, 稳态磁场对血管生成的影响并不一致. 然而
有趣的是, 从这些报道中我们发现了以下两个规律: (1) 在肿瘤相关小鼠模型中，其血管生成能够被稳态磁场 所抑制, 这可能是稳态磁场抑制肿瘤生长的重要机制. （2）在非肿瘤模型中，较高场强和/或长时间稳态磁场 处理能够促进血管生成. 下一步我们需要进行系统性 研究, 比较不同的磁场强度和处理时间在不同类型的 动物模型中的具体作用, 从而对此规律进行确认.

\section{2 动态磁场与血管生成}

动态磁场同样会影响血管生成. 而且, 由于动态磁 场参数的可变性(如磁场强度和频率等), 动态磁场对血 管生成呈现出各种不同的作用效果.

一些研究结果表明，血管生成会被特定参数的动 态磁场所抑制. 例如，2001年，Williams等人 ${ }^{[28]}$ 报道了 皮下植人鼠 $16 / \mathrm{C}$ 乳腺癌细胞的 $\mathrm{C} 3 \mathrm{H} / \mathrm{HeJ}$ 小鼠暴露于治 疗性电磁场会显著抑制血管生成和肿瘤生长. 2005年, 研究人员同样发现植人人MDA-MB231乳腺癌细胞的 裸鼠每日暴露于治疗性电磁场 $10 \mathrm{~min}$, 持续治疗 3 周, 可 以减少肿瘤血管生成，降低肿瘤生长速率和肿瘤细胞 向肺转移的程度 ${ }^{[29]}$. 2010年, $\mathrm{Hu}$ 等人 ${ }^{[30]}$ 报道了时变磁 场对小鼠肿瘤的生长具有有效抑制作用. 他们发现, 暴 露弱磁场(1 5 nT)的小鼠比暴露在假磁场或强磁场 (2 5 mT)的小鼠肿瘤形成减小, 肿瘤生长受到磁场强 度的影响, 并且传统光镜观察显示暴露在弱磁场并存

表 1 稳态磁场与血管生成的人/动物/组织研究 ${ }^{a)}$

Table 1 Static magnetic fields and angiogenesis in human/animal/tissue studies

\begin{tabular}{|c|c|c|c|c|c|}
\hline \multirow{2}{*}{ 人/动物/组织类型 } & \multirow{2}{*}{ 磁场参数 } & \multirow{2}{*}{ 磁场处理时间 } & \multicolumn{2}{|l|}{ 对血管生成的影响 } & \multirow{2}{*}{ 文献 } \\
\hline & & & 具体影响 & 总体效应 & \\
\hline \multirow{2}{*}{ 携带A-Mel-3肿瘤的仓鼠 } & \multirow{2}{*}{$587 \mathrm{mT}$} & $3 \mathrm{~h}$ & \multirow{3}{*}{ 肿瘤功能性血管密度降低 } & \multirow{7}{*}{ 抑制 } & {$[16]$} \\
\hline & & $2 \mathrm{~h}$ & & & {$[18]$} \\
\hline 携带A-Mel-3肿瘤的仓鼠 & $586 \mathrm{mT}$ & $3 \mathrm{~h}$ & & & [17] \\
\hline 鸡胚线毛尿囊膜 & \multirow{2}{*}{$0.2 \sim 0.4 \mathrm{~T}, 2.09 \mathrm{~T} / \mathrm{m}$} & $7,9 \mathrm{~d}$ & \multirow{2}{*}{ 模型中血管数量及血红蛋白量降低 } & & \multirow{2}{*}[19]{} \\
\hline C57BL小鼠(基质胶栓模型) & & $7,11 \mathrm{~d}$ & & & \\
\hline 鸡肧线毛尿囊膜 & $0.2 \mathrm{~T}$ & $3 \mathrm{~h}$ & $\begin{array}{c}\text { 抑制由前列腺素E1和胎牛血清刺激 } \\
\text { 诱导的血管生成反应 }\end{array}$ & & {$[24]$} \\
\hline 雄性c57B1/6小鼠(机械损伤) & $\begin{array}{c}20 \sim 60 \mathrm{mT} / 0.7 \mathrm{~cm} \text { 或 } \\
25 \sim 85 \mathrm{mT} / \mathrm{cm}\end{array}$ & $7 \mathrm{~d}$ & 降低皮肤微静脉功能长度密度 & & [25] \\
\hline ICR小鼠 & $4.7 \mathrm{~T}$ & $2 \mathrm{~d}$ & 胎儿胸骨中VEGF的免疫反应性增强 & & {$[26]$} \\
\hline 雄性Wistar鼠(缺血骨模型) & $180 \mathrm{mT}$ & 3周 & 侧支循环增加 & & {$[23]$} \\
\hline 慢性小腿溃疡患者 & $0.06 \sim 0.08 \mathrm{~T}$ & $12 \mathrm{~h} / \mathrm{d}$, 共 $15,25 \mathrm{~d}$ & 小腿部毛细血管显著增生 & 促进 & {$[22]$} \\
\hline 杂种狗颈总动脉内皮 & 强度不明, 0.025 T/cm²(交替排布) & 1 8周 & 促进血管内皮再生 & & [27] \\
\hline
\end{tabular}

a) 灰色区域代表抑制作用, 蓝色区域代表促进作用 
活的小鼠的毛细血管和肥大细胞数量少于暴露在强磁 场的小鼠，提示血管生成的改变可能导致肿瘤生长的 差异. 2014年, Cameron等人 ${ }^{[31]}$ 进一步研究了关于治疗 性电磁场装置对植人鼠 $16 / C$ 乳腺癌细胞的 $\mathrm{C} 3 \mathrm{H} / \mathrm{HeJ}$ 小 鼠的生长和血管形成的影响, 结果显示治疗性电磁场 应用降低血管体积分数并增加肿瘤的坏死体积，且应 用 $15 \mathrm{mT}$ 治疗性电磁场每天处理 $10 \mathrm{~min}$ 给出最大的抗 血管生成作用. 2016年, Stölting等人 ${ }^{[32]}$ 发现在肌肉损伤 小鼠模型身上仅用了 3 次 $20 \mathrm{~min}$ 的磁刺激(先 $10 \mathrm{~min} /$ $10 \mathrm{~Hz}$, 后 $10 \mathrm{~min} / 50 \mathrm{~Hz}$. 每次脉冲 $3 \mathrm{~s}$ 刺激, $6 \mathrm{~s}$ 休息)便可 以降低㓔痕内的新生血管的密度，并且显著减少炎症 浸润和创伤后痽痕的形成以改善肌肉再生.

同时，也有研究显示血管生成可能被动态磁场所 促进. 例如，2013年，Pan等人 ${ }^{[33]}$ 报道了用脉冲电磁场 处理后手术诱导的急性后肢缺血的糖尿病大鼠的后肢 新生血管标记物 CD 31 表达和碱性磷酸酶(alkaline phosphatase，AP)活性显著升高，表明脉冲电磁场能够 促进新血管形成. 2014年, 张建勇等人 ${ }^{[34]}$ 进行低频电磁 治疗动脉弹样硬化并肢体缺血模型兔的研究, 发现家 兔缺血肢体缺氧诱导因子 $1 \alpha$ 、血管内皮生长因子(vascular endothelial growth factor, VEGF)及血管内皮细胞 特有的表面标志 CD34表达上升. 同年， $\mathrm{Fu}$ 等人 ${ }^{[35]}$ 报道 了单脉冲电磁场处理 $(1 \mathrm{~T}$, 每天30次脉冲) 增加了移植 的坏死骨中新的血管形成. 2017 年, Dey等人 ${ }^{[36]}$ 发现脊 髓损伤大鼠使用极低频电磁场处理增加了脊髓损伤中 心周围区域的VEGF免疫反应活性和阳性细胞数量，提 示磁场可能促进了脊髓损伤后的血管生成. 2019年, Paras等人 ${ }^{[37]}$ 报道了 $1.9 \mathrm{GHz}$ 高频电磁场引起大鼠器官 的血管内皮细胞的体积密度和数量增加, 诱导了血管 生成. 此外, 2009 年, 郭影等人 ${ }^{[38]}$ 发现不同强度低频脉 冲磁场均能够促进体外培养大鼠骨髓源内皮祖细胞增 殖和提高内皮祖细胞成血管能力，但是 1.0 和 $1.4 \mathrm{mT}$ 组
作用强于 $1.8 \mathrm{mT}$ 组.

关于动态磁场影响血管生成的研究总结见表 2 和 3 . 动态磁场的可变参数较多，而目前的文献报道十 分有限，因此我们尚无法得到有关动态磁场与血管生 成的确切关系，需要进行更多的统一实验标准以及可 重复性强的随机对照实验以期确定适合的磁场参数推 动这一领域向前发展. 此外, 我们发现脉冲电磁场和高 频电磁场可以表现出良好的促进血管生成反应的潜能, 但是由于涉及强度、振幅、频率、所用设备的窗口和 信号波形的非线性变化，相关研究外推到临床设置的 严格理论基础有待被建立.

\section{2 磁场联合治疗与血管生成}

\section{1 磁场与药物的联合}

目前一些研究发现，与磁场单独处理或者药物单 独处理相比，磁场与药物的联合会取得更好的治疗效 果. 例如，2011年，Balanezhad等人 ${ }^{[54]}$ 发现0.04 T电磁 场可以增强丙戊酸钠对 CAM血管生成的抑制作用. 2014年, Mousavi等人 ${ }^{[55]}$ 报道了藏红花提取物和低频电 磁场联合作用人乳腺癌细胞后，血管内皮生长因子受 体2(vascular endothelial growth factor receptor-2, VEGFR2)基因表达降低，揭示该药物和磁场联合使用 具有抗血管生成潜能. 同年, Gellrich等人 ${ }^{[18]}$ 发现 587 $\mathrm{mT}$ 稳态磁场联合化疗药物紫杉醇可以显著降低功能 性肿瘤微血管密度. 但是也有研究表明, 某些药物的效 果并不会被磁场提高，甚至反而可能会出现拮抗效应. 2018年，Gellrich等人 ${ }^{[20]}$ 发现与单独的稳态磁场组和西 妥昔单抗组相比，稳态磁场与西妥昔单抗的联合对血 管生成并没有显著的影响. 他们认为, 稳态磁场可能影 响表皮生长因子受体的分子构象，从而阻碍西妥昔单 抗对受体的有效阻断. 这些效应之间的差异可能与生

表 2 动态磁场与血管生成的离体细胞研究 ${ }^{\mathrm{a})}$

Table 2 Dynamic magnetic field and angiogenesis in cells studies

\begin{tabular}{|c|c|c|c|c|c|}
\hline \multirow{2}{*}{ 生物样品 } & \multirow{2}{*}{ 磁场参数 } & \multirow{2}{*}{ 磁场处理时间 } & \multicolumn{2}{|c|}{ 对血管生成的影响 } & \multirow{2}{*}{ 文献 } \\
\hline & & & 具体影响 & 总体效应 & \\
\hline \multirow{3}{*}{ 人脐静脉内皮细胞 } & $2 \mathrm{mT}, 50 \mathrm{~Hz}$ & $6,12 \mathrm{~h}$ & 迁移和形成管状结构减少 & 抑制 & [39] \\
\hline & $1.2 \mathrm{mT}, 15 \mathrm{~Hz}$ & $7 \sim 10 \mathrm{~d}$ & 内皮细胞血管化程度增加 & & [40] \\
\hline & $1 \mathrm{mT}, 50 \mathrm{~Hz}$ & $12 \mathrm{~h}$ & 小管形成的程度增加 & 促进 & [41] \\
\hline 牛主动脉内皮细胞和人脐静脉内皮细胞 & $0.1 \mathrm{mT}, 15 \mathrm{~Hz}$ & 持续 $23 \mathrm{~d}$ & 促进血管化 & & [42] \\
\hline
\end{tabular}

a) 灰色区域代表抑制作用, 蓝色区域代表促进作用 
表 3 动态磁场与血管生成的动物/组织研究 ${ }^{\text {a) }}$

Table 3 Dynamic magnetic fields and angiogenesis in animal/tissue studies

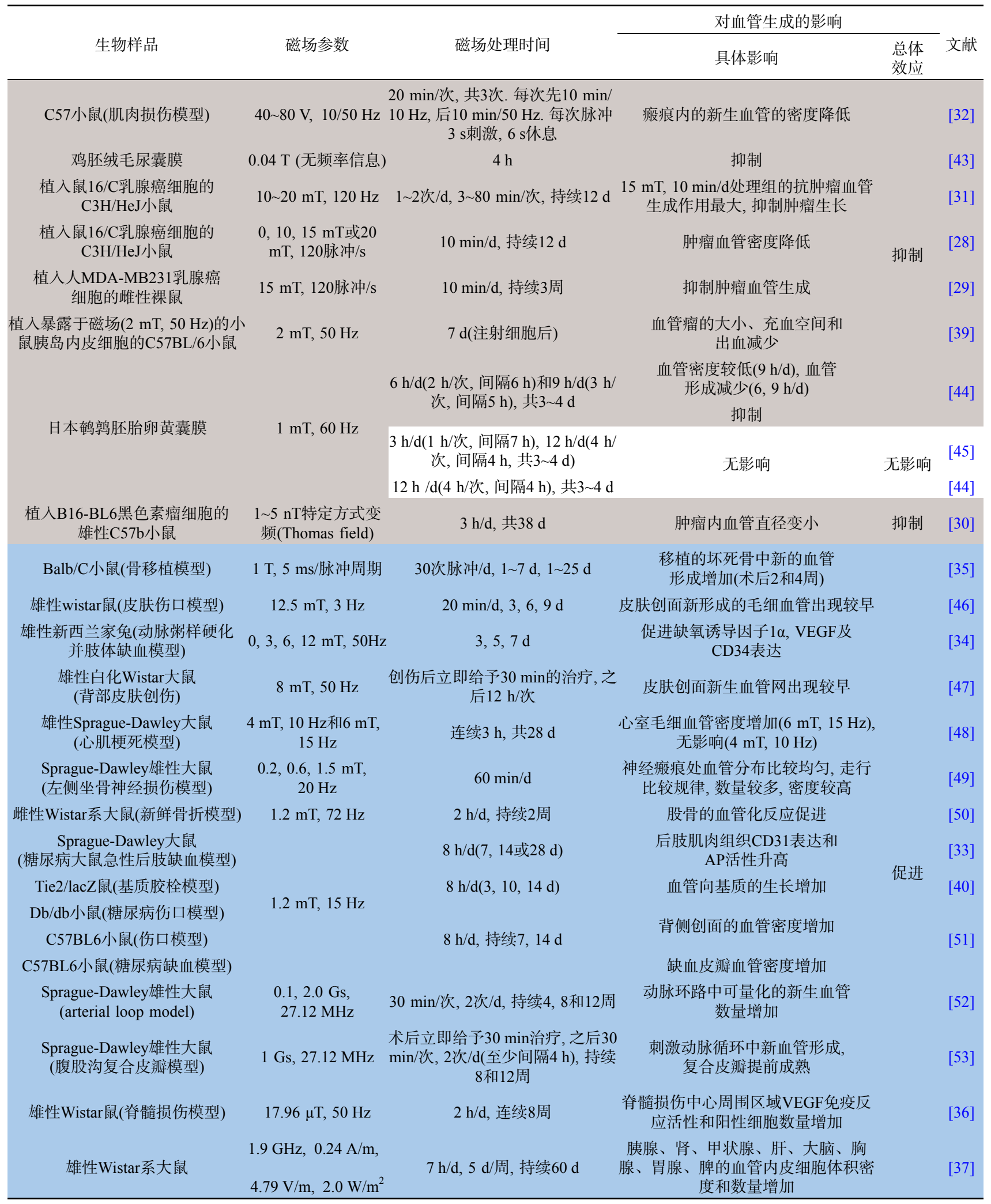

a) 灰色区域代表抑制作用, 蓝色区域代表促进作用, 无色区域代表无影响作用 
物样品类型、磁场参数或药物类型的差异等多种因素 有关，从目前仅有的几项关于稳态磁场与药物联合对 血管生成的研究还不足以得出任何确切结论, 因此还 需要进一步的系统性研究.

\section{2 磁场与放疗的联合}

目前关于磁场和辐照联合作用对血管生成影响的 研究十分匮乏, 但有研究表明磁场和放射疗法的联用 也能影响血管生成. 例如, 2005年的一项研究发现伽马 辐照治疗和电磁场治疗均能降低肿瘤内血管体积密 度 $^{[29]}$, 而且接受伽马辐照治疗的小鼠中, 每日持续使用 电磁场治疗可以抑制肿瘤血管体积密度的恢复. 换句 话说，电磁场联合伽马辐照治疗可以导致肿瘤血管生 成的持续和显著降低. 2006年，季百苗等人 ${ }^{[56]}$ 发现 0.6 $\mathrm{T} / 10 \mathrm{~Hz}$ 旋转磁场能促进Cs伽马射线放射损伤小鼠骨 髓内血管生成及造血组织的恢复.

\section{3 磁场与纳米材料的联合}

近年来关于纳米材料的研究发展迅速, 而磁场由 于其本身的可控性以及磁学性能等优势, 磁性纳米材 料可以在磁场的作用下，实现细胞标记、磁靶向、磁 响应和基因修饰等策略, 从而影响血管生成.

其中，稳态磁场联合纳米材料的主要优势在于稳 态磁场较稳定, 可变参数少, 而且不需要动力装置即可 进行长期作用. 例如, 2016年, Wang 等人 ${ }^{[57]}$ 将脂肪源性 干细胞(adipose-derived stem cells, ASCs)预先加载了超 顺磁性氧化铁纳米颗粒，发现外用稳态磁场可增强 ASCs诱导的血管生成反应. Yun等人 ${ }^{[58]}$ 研究发现稳态 磁场与聚己内酯/磁性纳米颗粒制成的磁性纳米复合支 架刺激成骨细胞分化，并促进内皮细胞的血管生成反 应，包括VEGF和血管生成素-1基因的表达和毛细血管 的形成. 2017年, Hao等人 ${ }^{[59]}$ 证明了磁性纳米纤维支架 与磁场联合调控巨噬细胞的功能，有利于血管生成和 成骨. 2019年, Zhang等人 ${ }^{[60]}$ 利用体外磁铁引导心肌梗 死雌性大鼠模型中移植的磁性纳米粒子标记内皮祖细 胞, 发现梗死边缘区毛细血管密度增加, 促血管生成因 子表达上调, 促进血管生成. 同年, Rieck等人 ${ }^{[61]}$ 在体内 实验中利用慢病毒和磁性纳米颗粒复合物结合稳态磁 场对含 $\mathrm{SH} 2$ 结构域的酪氨酸蛋白磷酸酶进行局部RNAi 基因敲除, 可以减少血管生成.

动态磁场联合纳米材料的主要优势在于动态磁场 可以进行动态的刺激, 而且刺激性较强. 例如, 2016年,
Xie等人 ${ }^{[62]}$ 在交变磁场下，通过反复注射磁性纳米材料 MNCs@PEG和MNCs@RGD进行肿瘤靶向热疗，充足 的温度升高可诱导肿瘤细胞凋亡，抑制肿瘤血管生成. 2017年, Liang等人 ${ }^{[63]}$ 将聚乳酸-乙醇酸-磁性微球结合 经导管动脉栓塞(transcatheter arterial embolization, TAE)和磁消融的协同治疗策略应用于免原位VX2肝肿 瘤, 实验结果表明, 在经导管动脉栓塞后暴露于交变磁 场的情况下, 体内和体外肿瘤边缘均可被加热, 而在体 内肿瘤附近的正常肝实质中，其温度的升高几乎可以 忽略不计. 足够的温度升高诱导肿瘤细胞凋亡; 与单纯 TAE组相比, 可进一步抑制肿瘤血管生成, 导致坏死.

此外, 动态磁场和稳态磁场组合起来形成的复合磁 场联合纳米材料影响血管生成. 例如，2018年，Luo等 人 $^{[64]}$ 构建了一种负载有超顺磁性质粒基因微球的人工 骨支架, 磁性微球在支架内在振荡磁场和稳态磁场作用 下产生磁性微动, 促进微球释放质粒基因转染周围细 胞，导致血管内皮生长因子蛋白表达，从而促进支架内 血管生成. 2019年, Chen等人 ${ }^{[65]}$ 通过体内动物实验证实, 稳态磁场与振荡磁场的联合作用改善了优化后的超顺 磁性壳聚糖纳米粒/质粒明胶微球在支架内的血管化效 果, 尤其是术后6周骨缺损部位有明显新生血管形成.

关于磁场联合治疗与血管生成的相关研究总结见 表4.

\section{3 磁场影响血管生成的机制}

血管生成是涉及多种因子和细胞的复杂过程，这 一过程需要血管舒张、内皮通透性和内皮支持、内皮 细胞的增殖和迁移及管腔形成、内皮生存和内皮分化 以及血管重塑等多个步骤完成 ${ }^{[70]}$. “血管开关的平衡假 说”认为血管生成主要是通过促血管生成因子和抑血 管生成因子之间的平衡进行调节，当促血管生成因子 与抑血管生成因子的作用达到平衡时，血管生成开关 关闭; 当净平衡向有利于血管生成的方向倾斜时, 血管 生成开关打开 ${ }^{[71]}$.

内皮细胞是血管生成过程中重要的效应细胞，可 以释放促进和抗血管生成分子，其增殖是血管生成过 程中的关键步骤. 目前有多项研究表明, 磁场可以影响 内皮细胞增殖. 例如, 2004年, Tepper等人 ${ }^{[40]}$ 发现脉冲电 磁场在体外可使内皮细胞增殖程度增加, 并且可能通 过刺激内皮细胞释放成纤维细胞生长因子-2(fibroblast growth factor-2, FGF-2)、诱导周围组织的旁分泌和自 分泌改变来促进血管生成. 2015 年， $\mathrm{Li}$ 等人 ${ }^{[72]}$ 发现 1.8 
表 4 磁场联合治疗与血管生成

Table 4 Magnetic field combination therapy and angiogenesis

\begin{tabular}{|c|c|c|c|c|c|c|c|c|}
\hline \multirow{2}{*}{$\begin{array}{l}\text { 联合 } \\
\text { 作用 }\end{array}$} & \multirow[t]{2}{*}{ 磁场类型 } & \multirow[t]{2}{*}{ 联合作用类型 } & \multirow[t]{2}{*}{ 生物样品 } & \multirow[t]{2}{*}{ 磁场参数 } & \multirow[t]{2}{*}{ 磁场处理时间 } & \multicolumn{2}{|c|}{$\begin{array}{c}\text { 对药物/辐照/纳米材料等在 } \\
\text { 血管生成中作用的影响 }\end{array}$} & \multirow[t]{2}{*}{ 文献 } \\
\hline & & & & & & 具体影响 & 总体效应 & \\
\hline \multirow{6}{*}{ 药物 } & \multirow{3}{*}{ 稳态磁场 } & 西妥昔单抗 & $\begin{array}{c}\text { 携带LLC-1 肿瘤的雄性 } \\
\text { C57B1/6 小鼠 }\end{array}$ & $587 \mathrm{mT}$ & $\begin{array}{c}35 \mathrm{~min} / \mathrm{d} \\
(\text { 第3 11 d), } \\
120 \mathrm{~min} / \mathrm{d} \\
(\text { 第3,6,9 d) }\end{array}$ & 无影响 & 无影响 & {$[20]$} \\
\hline & & $\begin{array}{c}\text { 磁性阳离子脂质体负载 } \\
\text { 的化疗药物长春新碱 }\end{array}$ & $\begin{array}{c}\text { 植人B1-F10黑色素瘤 } \\
\text { 细胞的SCID小鼠 }\end{array}$ & $1.2 \mathrm{~T}$ & $1 \mathrm{~h}$ & $\begin{array}{c}\text { 与未使用药物和磁体的对 } \\
\text { 照组相比, 肿瘤血管数量 } \\
\text { 减少 }\end{array}$ & \multirow{5}{*}{$\begin{array}{l}\text { 促进 } \\
\text { 药效 }\end{array}$} & {$[66]$} \\
\hline & & 紫杉醇 & 携带A-Mel-3肿瘤的仓鼠 & $587 \mathrm{mT}$ & $2 \mathrm{~h}$ & $\begin{array}{c}\text { 促进紫杉醇降低功能性肿 } \\
\text { 瘤微血管密度的作用 }\end{array}$ & & {$[18]$} \\
\hline & 旋转磁场 & 5-氟尿嘧啶(5-FU) & 雄性C57 BL6/J小鼠 & $0.6 \mathrm{~T}, 10 \mathrm{~Hz}$ & $\begin{array}{c}1 \mathrm{~h} / \text { 次, } 2 \text { 次 } / \mathrm{d}, \\
\text { 共 } 30 \mathrm{~d}\end{array}$ & $\begin{array}{c}\text { 促进化疗损伤小鼠股骨骨 } \\
\text { 髓内的血管生成 }\end{array}$ & & {$[67]$} \\
\hline & \multirow{2}{*}{$\begin{array}{l}\text { 极低频 } \\
\text { 电磁场 }\end{array}$} & 丙戊酸钠 & 鸡胚线毛尿囊膜 & $\begin{array}{l}0.04 \text { T(无具 } \\
\text { 体频率信息) }\end{array}$ & $4 \mathrm{~h}$ & $\begin{array}{c}\text { 增强丙戊酸钠抑制血管生 } \\
\text { 成作用 }\end{array}$ & & {$[54]$} \\
\hline & & 藏红花 & 人乳腺癌MCF7细胞 & $0.04 \mathrm{~T}, 50 \mathrm{~Hz}$ & $1 \mathrm{~h}$ & $\begin{array}{l}\text { 增加藏红花对MCF7细胞 } \\
\text { VEGFR2表达的抑制作用 }\end{array}$ & & {$[55]$} \\
\hline \multirow{2}{*}{$\begin{array}{l}\text { 辐照 } \\
\text { 联合 }\end{array}$} & 治疗电磁场 & $\begin{array}{c}200 \text { cGy伽马射线 } \\
\text { (每隔 } 1 \mathrm{~d}, \text { 共 } 800 \mathrm{cGy} \text { ) }\end{array}$ & $\begin{array}{c}\text { 植人人MDA-MB231 } \\
\text { 乳腺癌细胞的雌性裸鼠 }\end{array}$ & $\begin{array}{c}15 \mathrm{mT}, 120 \text { 脉 } \\
\text { 冲/秒 }\end{array}$ & $\begin{array}{l}10 \mathrm{~min} / \mathrm{d} \text {, } \\
\text { 持续3周 }\end{array}$ & $\begin{array}{c}\text { 抑制放射治疗后肿瘤内血. } \\
\text { 管体积密度降低的恢复 }\end{array}$ & \multirow{2}{*}{$\begin{array}{l}\text { 促进辐 } \\
\text { 照效果 }\end{array}$} & [29] \\
\hline & 旋转磁场 & $6.5 \mathrm{~Gy} \mathrm{Cs}$ 伽马射线 & 雄性C57 BL6/J小鼠 & $0.6 \mathrm{~T}, 10 \mathrm{~Hz}$ & $\begin{array}{c}1 \mathrm{~h} / \text { 次, 2次/ } \mathrm{d}, \\
\text { 共 } 30 \mathrm{~d} \\
\end{array}$ & $\begin{array}{c}\text { 促进放射损伤小鼠骨髓内 } \\
\text { 血管生成 } \\
\end{array}$ & & {$[56]$} \\
\hline \multirow{7}{*}{$\begin{array}{l}\text { 纳米 } \\
\text { 材料 } \\
\text { 联合 }\end{array}$} & \multirow{7}{*}{ 稳态磁场 } & $\begin{array}{c}\text { 磁性纳米粒子标记的 } \\
\text { 内皮祖细胞 }\end{array}$ & 心肌梗死雌性大鼠模型 & $0.39 \mathrm{~T}$ & $1 \mathrm{~h}$ & $\begin{array}{c}\text { 梗死边缘区毛细血管密度 } \\
\text { 增加, 促血管生成因子表 } \\
\text { 达上调 }\end{array}$ & \multirow{7}{*}{$\begin{array}{l}\text { 促进纳米 } \\
\text { 材料作用 }\end{array}$} & {$[60]$} \\
\hline & & $\begin{array}{l}\text { ferumoxide标记的人神 } \\
\text { 经干细胞(hNSCs) }\end{array}$ & $\begin{array}{c}\text { 脑中动脉阻塞(MCAO) } \\
\text { 中风大鼠模型 }\end{array}$ & $0.32 \mathrm{~T}$ & $28 \mathrm{~d}$ & $\begin{array}{c}\text { 大脑中内皮细胞特异性蛋 } \\
\text { 白 } \mathrm{vWF} \text { 阳性细胞数量明显 } \\
\text { 增加 }\end{array}$ & & {$[68]$} \\
\hline & & $\begin{array}{c}\text { 加载超顺磁性氧化铁 } \\
\text { (SPIO)纳米颗粒的 } \\
\text { 脂肪源性干细胞 }\end{array}$ & 心肌梗死雌性大鼠模型 & $0.1 \mathrm{~T}$ & 4周 & $\begin{array}{c}\text { 增强脂肪源性干细胞诱导 } \\
\text { 的血管生成反应 }\end{array}$ & & {$[57]$} \\
\hline & & $\begin{array}{c}\text { 慢病毒和磁性纳米 } \\
\text { 颗粒复合物 }\end{array}$ & $\begin{array}{l}\text { C57BL/6或eNOS/ } \\
\text { 小鼠主动脉 }\end{array}$ & 约 $750 \mathrm{~T} / \mathrm{m}$ & $6 \mathrm{~d}$ & $\begin{array}{c}\text { 血管内皮中VEGF过表达 } \\
\text { 诱导血管生成 }\end{array}$ & & {$[69]$} \\
\hline & & $\begin{array}{c}\text { 聚己内酯/磁性纳米颗 } \\
\text { 粒制成的磁性纳米复合 } \\
\text { 支架 }\end{array}$ & 成骨细胞 & $15 \mathrm{mT}$ & $3 \mathrm{~d}$ & $\begin{array}{c}\text { 促进内皮细胞的血管生成 } \\
\text { 反应 }\end{array}$ & & {$[58]$} \\
\hline & & \multirow[t]{2}{*}{ 磁性纳米纤维支架 } & 雄性C57小鼠 & 5 和 $10 \mathrm{mT}$ & $21 \mathrm{~d}$ & 增强血管生成反应 & & \\
\hline & & & $\begin{array}{c}\text { 小鼠单核巨噬细胞系 } \\
\text { (RAW264.7) }\end{array}$ & & $\begin{array}{l}72 \mathrm{~h}(12 \mathrm{~h} \text { 间隔 } \\
\text { 内交替放置或 } \\
\text { 移开磁铁) }\end{array}$ & $\begin{array}{c}\text { 促进内皮细胞的血管 } \\
\text { 生成反应 }\end{array}$ & & {$[59]$} \\
\hline
\end{tabular}

$\mathrm{mT} / 15 \mathrm{~Hz}$ 的脉冲磁场可以加速心肌微血管内皮细胞 (cardiamicrovascular endothelial cells, CMECs)和心肌细 胞(cardiac myocytes, CMs)的增殖和迁移, 对CMECs增 殖和迁移既有直接的自分泌有丝分裂作用，也有间接 的旁分泌作用，对CMECs与 $\mathrm{CMs}$ 间通讯的影响部分依 赖于FGF-2且不依赖于VEGF.

但是，由于磁场与内皮细胞增殖的实验结果五花 八门，从稳态磁场(表5)和动态磁场(表6)两方面，目前
都还无法从磁场参数、作用时间等得出磁场对内皮细 胞增殖影响的规律. 这可能与不同研究中所采用的处 理方式(加磁时间、间隔时间、总时长)、磁场参数(强 度、梯度、方向、分布)等多种因素有关.

磁场可能通过影响与血管生成相关的基因表达及 信号传导来影响血管生成. 例如, $0.2 \mathrm{~T}$ 静磁场会抑制前 列腺素E1和胎牛血清刺激的血管生成，研究者推测磁 场导致的抑制作用可能发生在进行血管生成所需的生 
表 5 稳态磁场与内皮细胞增殖 ${ }^{a)}$

Table 5 Static magnetic field and endothelial cell proliferation

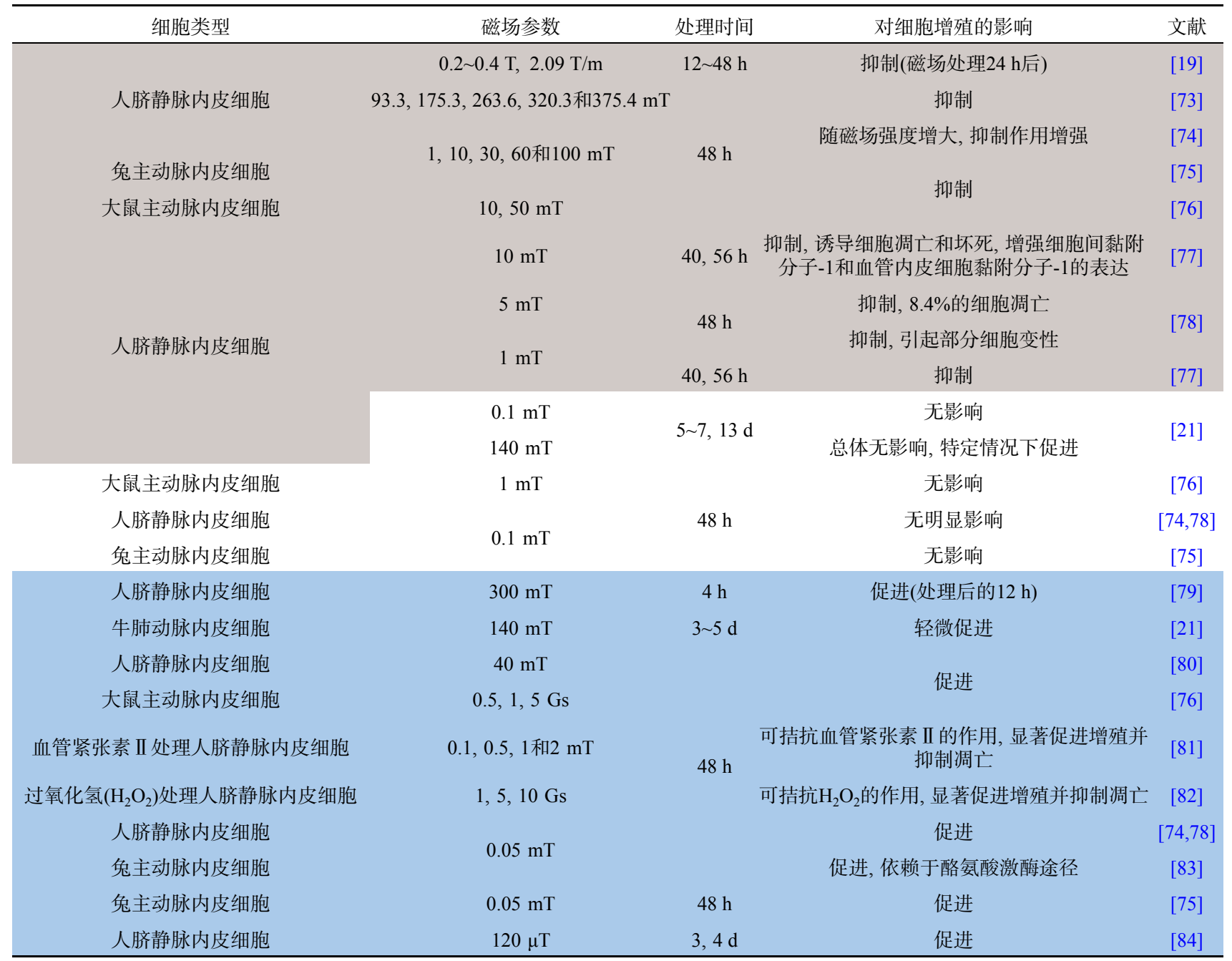

a) 灰色区域代表抑制作用, 蓝色区域代表促进作用, 无色区域代表无影响作用

长因子前列腺素信号传导途径的下游 ${ }^{[24]}$. 2008年, Callaghan等人 ${ }^{[51]}$ 研究表明在糖尿病和正常情况下, 脉冲电 磁场能够通过上调FGF-2介导的血管生成来加速伤口 愈合. 2010年, Goto等人 ${ }^{[90]}$ 研究发现, 脉冲电磁场可上 调小鼠骨髓中血管生成素-2和FGF-2, 但不上调内皮特 异性酪氨酸激酶受体、血管生成素-1或VEGF. 这些结 果提示，脉冲电磁场可在骨髓中诱导血管生成倾向的 环境，而不会产生包括缺氧或血管扩张在内的侵人性 影响. 2013年，Pan等人 ${ }^{[33]}$ 发现，脉冲电磁场增强了糖 尿病大鼠急性后肢缺血相关的灌注和血管生成，与上 调FGF-2表达和激活ERK1/2通路有关. 此外, Bekhite等 人 ${ }^{[91]}$ 研究发现, 稳态电磁场可升高细胞内活性氧(reactive oxygen species, ROS)水平, 激活ERK1/2通路调节
VEGF的表达，而VEGF在胚胎干细胞分化过程中对肥 大软骨血管新生至关重要.

此外，磁场也可能通过影响细胞膜以及跨膜信号 转导进而影响血管生成. 2013年, Delle Monache等 人 ${ }^{[39]}$ 收集了关于极低频磁场对VEGF激活的信号通路 的数据, 特别是磁场暴露显著降低了VEGFR2的表达和 激活水平，提示磁场对细胞膜上VEGF受体有直接或间 接影响.

人们已知稳态磁场可以影响多种细胞功能，如基 因表达、细胞定位和细胞间关系的变化 ${ }^{[92]}$. 此外, 稳态 磁场还可以影响抗氧化防御系统 ${ }^{[8]}$ 和钙水平变化 ${ }^{[93]}$. 由于钙在生物系统中起着至关重要的作用, 特别是在 信号转导级联反应中，研究人员猜想磁场可能通过诱 
表 6 动态磁场与内皮细胞增殖 ${ }^{a)}$

Table 6 Dynamic magnetic field and endothelial cell proliferation

\begin{tabular}{|c|c|c|c|c|}
\hline 细胞类型 & 磁场参数 & 处理时间 & 对细胞增殖的影响 & 文献 \\
\hline 小鼠胰岛内皮细胞 & $2 \mathrm{mT}, 50 \mathrm{~Hz}$ & $72 \mathrm{~h}$ & 抑制 & [39] \\
\hline \multirow{6}{*}{ 人脐静脉内皮细胞 } & \multirow{2}{*}{20,40 和 $60 \mathrm{mT}, 50 \mathrm{~Hz}$} & \multirow{2}{*}{$10,20,30 \mathrm{~min} / \mathrm{d}$} & $\begin{array}{c}\text { 增殖随时间延长呈现先促进后抑制的 } \\
\text { 趋势, } 60 \mathrm{mT} \text { 组作用最强 }\end{array}$ & {$[85]$} \\
\hline & & & $\begin{array}{c}\text { DNA合成量随作用时间延长呈现先促进 } \\
\text { 后抑制的趋势 }\end{array}$ & {$[86]$} \\
\hline & $2 \mathrm{mT}, 50 \mathrm{~Hz}$ & $1,6,12 \mathrm{~h}$ & \multirow{2}{*}{ 抑制 } & \multirow{2}{*}{ [39] } \\
\hline & $1 \mathrm{mT}, 50 \mathrm{~Hz}$ & $24 \mathrm{~h}$ & & \\
\hline & $1.2 \mathrm{mT}, 15 \mathrm{~Hz}$ & $24 \mathrm{~h}$ & \multirow{2}{*}{ 促进 } & [40] \\
\hline & $1 \mathrm{mT}, 50 \mathrm{~Hz}$ & $12 \mathrm{~h}$ & & [41] \\
\hline \multirow{4}{*}{ 大鼠心肌微血管内皮细胞 } & $1.0,1.4,1.8 \mathrm{mT}, 15 \mathrm{~Hz}$ & $4 \mathrm{~h} / \mathrm{d}, 3 \mathrm{~d}$ & $\begin{array}{c}1.0 \mathrm{mT} \text { 无明显影响, } 1.4,1.8 \mathrm{mT} \text { 促进 } \\
\text { 细胞增殖、迁移及DNA合成能力 }\end{array}$ & [87] \\
\hline & $0.8,1.4,1.8 \mathrm{mT}, 15 \mathrm{~Hz}$ & $4 \mathrm{~h} / \mathrm{d}, 4 \mathrm{~d}$ & $\begin{array}{c}\text { 促进增殖和增强细胞活力, 下调细胞 } \\
\text { 缝隙连接蛋白 } 43(\mathrm{Cx} 43) \text { 表达 }\end{array}$ & {$[88]$} \\
\hline & $0.8,1.4,1.8 \mathrm{mT}, 15 \mathrm{~Hz}$ & $4 \mathrm{~h} / \mathrm{d}, 7 \mathrm{~d}$ & 促进增殖与增强细胞活力, 上调 $\mathrm{Cx} 43$ 表达 & [89] \\
\hline & $1.8 \mathrm{mT}, 15 \mathrm{~Hz}$ & $2 \mathrm{~h} / \mathrm{d}, 5 \mathrm{~d}$ & 促进 & [72] \\
\hline
\end{tabular}

a) 灰色区域代表抑制作用, 蓝色区域代表促进作用

导钻信号通路进一步调控血管生成 ${ }^{[94]}$. 总的来讲, 这些 发现虽然揭示了部分磁场影响血管生成的可能作用机 制(图2), 但还不够明确, 例如不同参数的磁场在不同类 型的血管生成中的作用机制是否不同以及有何不同. 对此, 我们需要进一步的探索与论证, 得到更深人和全 面的认识.

此外, 现有的多项动物水平上的研究都显示了肿 瘤组织的血管生成可以被稳态磁场和动态磁场所抑制, 但是在机制方面的研究极其缺乏. 病理性血管生成依 赖于许多与生理性血管生成相同的过程. 在缺血和缺 氧条件下, 启动一系列高度协调的细胞功能, 导致新血 管的建立和氧与营养的供应，是生理性和病理性血管 生成的主要驱动因素. 在生理条件下，血管灌注后，细 胞功能和组成的一系列事件和变化逐渐消退. 相比之 下, 在肿瘤血管生成等病理条件下, 血管生成级联反应 是持续不断的，部分是由肿瘤分泌因子和肿瘤缺氧引 起的 ${ }^{[95]}$, 而且肿瘤血管在结构和功能上都存在高度异 常, 导致可能继续产生缺氧区. 抗血管生成治疗被认为 可使肿瘤血管系统暂时正常化，从而使其更有效地供 氧和给药 ${ }^{\left[{ }^{[96]}\right.}$. 此外, 生理和肿瘤相关血管生成的一个重 要区别可能在于生理性血管生成更依赖于VEGF信号, 而肿瘤血管生成可以通过持续募集髓样细胞和上调替 代性血管生长分子将其依赖性从 VEGF转移到其他促 血管生成途径 ${ }^{[95]}$. 并且, 那些被越来越多地认为在调节

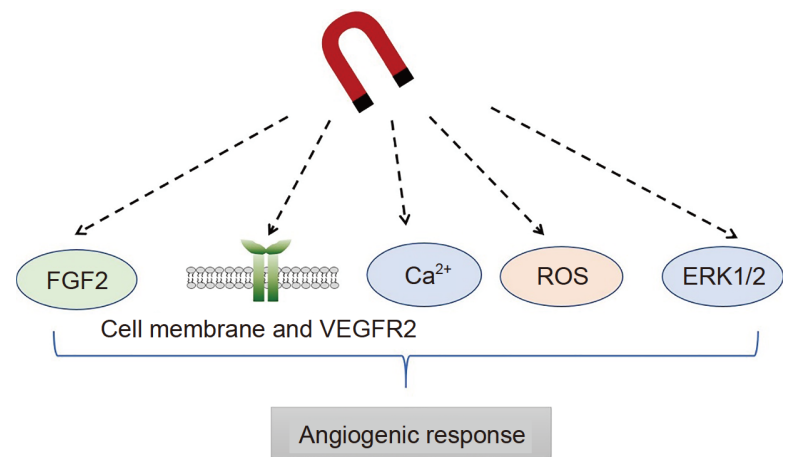

图 2 磁场影响血管生成的可能分子机制

Figure 2 Speculation of the molecular mechanisms of magnetic field affecting angiogenesis

肿瘤的顽固性和抗血管生成治疗的耐药性方面起重要 作用的通路，在发育和其他类型的生理性血管生成中 可能没有同等重要的作用 ${ }^{[95]}$. 这些区别都有可能导致 磁场在肿瘤血管生成与其他类型血管生成中作用不同. 未来人们需要进一步全面系统地研究不同参数磁场对 肿瘤血管生成以及各种不同类型血管生成的影响及其 机制, 为肿瘤治疗提供新思路和新方法.

\section{4 总结与展望}

总体来说, 由于多种参数的变化, 如磁场频率、强 度、处理时间、生物样品类型和检测方法等，磁场与 血管生成之间的准确关系还没有统一的结论和解释. 
然而, 从有限的报道中可以发现, 多种磁场都显示了抑 制肿瘤组织内血管生成的作用，而长时间或者较高磁 场强度的稳态磁场对其他多种生理病理条件下的血管 生成有促进的趋势，说明不同参数的磁场在不同类型 的血管生成中有着不同的作用，也提示除了磁外科之 外，磁场在未来有希望作为一种潜在的辅助治疗方法,
在癌症、缺血性疾病和创伤愈合等多种疾病中发挥作 用. 然而，由于目前实验证据还不够系统全面，效果还 不够确定, 机制也并不清楚, 因此进一步系统性地研究 不同磁场处理参数对血管生成的影响并对其机制进行 论证，对了解和开发磁场在未来作为治疗血管生成的 新方法和新策略至关重要.

\section{参考文献}

1 Zhang X, Yarema K, Xu A. Biological Effects of Static Magnetic Fields. Singapore: Springer, 2017. 3-6

2 Zhang X, Yarema K, Xu A. Biological Effects of Static Magnetic Fields (in Chinese). Beijing: Science Press, 2018. 1-4 [张欣, Yarema K, 许安. 稳 态磁场的生物学效应. 北京: 科学出版社, 2018. 1-4]

3 Zhang L, Ji X, Yang X, et al. Cell type- and density-dependent effect of 1 T static magnetic field on cell proliferation. Oncotarget, 2017, 8: 1312613141

4 Sullivan K, Balin A K, Allen R G. Effects of static magnetic fields on the growth of various types of human cells. Bioelectromagnetics, 2011, 32: $140-147$

5 Zhang L, Wang J, Wang H, et al. Moderate and strong static magnetic fields directly affect EGFR kinase domain orientation to inhibit cancer cell proliferation. Oncotarget, 2016, 7: 41527-41539

6 Tian X, Wang D, Feng S, et al. Effects of 3.5-23.0 T static magnetic fields on mice: A safety study. Neuroimage, 2019, 199: 273-280

7 Zhang L, Hou Y, Li Z, et al. $27 \mathrm{~T}$ ultra-high static magnetic field changes orientation and morphology of mitotic spindles in human cells. eLife, 2017, 6: e22911

8 Wang H, Zhang X. Magnetic fields and reactive oxygen species. Int J Mol Sci, 2017, 18: 2175

9 Wang S, Luo J, Lv H, et al. Safety of exposure to high static magnetic fields (2 T-12 T): A study on mice. Eur Radiol, 2019, 29: 6029-6037

10 Carmeliet P, Jain R K. Molecular mechanisms and clinical applications of angiogenesis. Nature, 2011, 473: 298-307

11 Risau W. Mechanisms of angiogenesis. Nature, 1997, 386: 671-674

12 Carmeliet P. Angiogenesis in health and disease. Nat Med, 2003, 9: 653-660

13 Folkman J. Opinion: Angiogenesis: An organizing principle for drug discovery? Nat Rev Drug Discov, 2007, 6: 273

14 Yan X P, Shang P, Shi A H, et al. Exploration and establishment of magnetic surgery (in Chinese). Chin Sci Bull, 2019, 64: 815-826 [严小鹏, 商 澎, 史爱华, 等. 磁外科学体系的探索与建立. 科学通报, 2019, 64: 815-826]

15 Yan X P, Liu W Y, Li D C, et al. Magnamosis combined with endoscopy: A new endoscopic technique in digestive surgery (in Chinese). World Chin J Digest, 2014, 22: 2716-2721 [严小鹏, 刘雯雁, 李涤尘, 等. 消化外科手术的内镜化途径:磁吻合联合内镜. 世界华人消化杂志, 2014, 22 2716-2721]

16 Strieth S, Strelczyk D, Eichhorn M E, et al. Static magnetic fields induce blood flow decrease and platelet adherence in tumor microvessels. Cancer Biol Ther, 2008, 7: 814-819

17 Strelczyk D, Eichhorn M E, Luedemann S, et al. Static magnetic fields impair angiogenesis and growth of solid tumors in vivo. Cancer Biol Ther, 2009, 8: 1756-1762

18 Gellrich D, Becker S, Strieth S. Static magnetic fields increase tumor microvessel leakiness and improve antitumoral efficacy in combination with paclitaxel. Cancer Lett, 2014, 343: 107-114

19 Wang Z, Yang P, Xu H, et al. Inhibitory effects of a gradient static magnetic field on normal angiogenesis. Bioelectromagnetics, 2009, 30: 446-453

20 Gellrich D, Schmidtmayer U, Eckrich J, et al. Modulation of exposure to static magnetic field affects targeted therapy of solid tumors in vivo. Anticancer Res, 2018, 38: 4549-4555

21 Balyasnikova I V, Krotov K A, Danilov S M. Effect of a static magnetic field on the growth rate andin vitro angiogenesis of endothelial cells. Bull Exp Biol Med, 1994, 117: 110-113

22 Liang Y Q, Yuan Y H, Zhang W Y, et al. Observation on histopathology of static magnetic field for chronic lower leg ulcer (in Chinese). Chin J Phys Ther, 1994, 17: 24-25 [梁应权, 袁云华, 张文玉, 等. 静磁场对慢性小腿溃疡的疗效及组织病理观察. 中华理疗杂志, 1994, 17: 24-25]

$23 \mathrm{Xu} \mathrm{S}$, Tomita N, Ikeuchi K, et al. Recovery of small-sized blood vessels in ischemic bone under static magnetic field. Evid-Based Compl Alternat Med, 2007, 4: 59-63

24 Ruggiero M, Bottaro D P, Liguri G, et al. $0.2 \mathrm{~T}$ magnetic field inhibits angiogenesis in chick embryo chorioallantoic membrane Bioelectromagnetics, 2004, 25: 390-396

25 Morris C E, Skalak T C. Chronic static magnetic field exposure alters microvessel enlargement resulting from surgical intervention. J Appl Physiol, 
2007, 103: 629-636

26 Okazaki R, Ootsuyama A, Uchida S, et al. Effects of a 4.7 T static magnetic field on fetal development in ICR mice. J Radioat Res, 2001, 42: 273283

27 Matsumoto H, Kira K, Kondoh K, et al. Effects of alternately aligned static micromagnetic fields on intravascular endothelial lining. Angiology, 1992, 43: 757-764

28 Williams C D, Markov M S, Hardman W E, et al. Therapeutic electromagnetic field effects on angiogenesis and tumor growth. Anticancer Res, 2001, 21: 3887-3891

29 Cameron I L, Sun L Z, Short N, et al. Therapeutic electromagnetic field (TEMF) and gamma irradiation on human breast cancer xenograft growth, angiogenesis and metastasis. Cancer Cell Int, 2005, 5: 23

$30 \mathrm{Hu}$ J H, St-Pierre L S, Buckner C A, et al. Growth of injected melanoma cells is suppressed by whole body exposure to specific spatial-temporal configurations of weak intensity magnetic fields. Int J Radiat Biol, 2010, 86: 79-88

31 Cameron I L, Markov M S, Hardman W E. Optimization of a therapeutic electromagnetic field (EMF) to retard breast cancer tumor growth and vascularity. Cancer Cell Int, 2014, 14: 125

32 Stölting M N L, Arnold A S, Haralampieva D, et al. Magnetic stimulation supports muscle and nerve regeneration after trauma in mice. Muscle Nerve, 2016, 53: 598-607

33 Pan Y, Dong Y, Hou W, et al. Effects of PEMF on microcirculation and angiogenesis in a model of acute hindlimb ischemia in diabetic rats. Bioelectromagnetics, 2013, 34: 180-188

34 Zhang J Y, Peng H, Meng D K, et al. Low-frequency magnetic fields promote neovascularization in a rabbit model of atherosclerosis combined with limb ischemia (in Chinese). Chin J Tissue Eng Res, 2014, 18: 4375-4382 [张建勇, 彭辉, 孟德凯, 等. 动脉弹样硬化并肢体缺血模型兔接受 低频电磁场刺激促进新生血管形成. 中国组织工程研究, 2014, 18: 4375-4382]

35 Fu Y C, Lin C C, Chang J K, et al. A novel single pulsed electromagnetic field stimulates osteogenesis of bone marrow mesenchymal stem cells and bone repair. PLoS One, 2014, 9: e91581

36 Dey S, Bose S, Kumar S, et al. Extremely low frequency magnetic field protects injured spinal cord from the microglia- and iron-induced tissue damage. Electromagn Biol Med, 2017, 36: 330-340

37 Paras S, Vojinovic N, Amidzic L. Impact of high frequency electromagnetic fields on process of angiogenesis. In: BadnjevicA, Skrbic R, Pokvic L G. Proceedings of the International Conference on Medical and Biological Engineering. Cham: Springer, 2019. 37-42

38 Guo Y, Li F, Guo W Y, et al. Effects of low frequency pulse magnetic fields on proliferation and tube formation of rat bone marrow derived endothelial progenitor cells (in Chinese). South China J Cardiovasc Dis, 2009, 15: 131-135 [郭影, 李飞, 郭文怡, 等. 低频脉冲磁场对大鼠骨髓 源内皮祖细胞增殖和体外血管化的影响. 岭南心血管病杂志, 2009, 15: 131-135]

39 Delle Monache S, Angelucci A, Sanità P, et al. Inhibition of angiogenesis mediated by extremely low-frequency magnetic fields (ELF-MFs). PLoS One, 2013, 8: e79309

40 Tepper O M, Callaghan M J, Chang E I, et al. Electromagnetic fields increase in vitro and in vivo angiogenesis through endothelial release of FGF2. FASEB J, 2004, 18: 1231-1233

41 Delle Monache S, Alessandro R, Iorio R, et al. Extremely low frequency electromagnetic fields (ELF-EMFs) induce in vitro angiogenesis process in human endothelial cells. Bioelectromagnetics, 2008, 29: 640-648

42 Yen-Patton G P A, Patton W F, Beer D M, et al. Endothelial cell response to pulsed electromagnetic fields: Stimulation of growth rate and angiogenesis in vitro. J Cell Physiol, 1988, 134: 37-46

43 Balanezhad S Z, Parivar K, Baharara J, et al. The effect of extremely low frequency electromagnetic field on angiogenesis. Res J Environ Sci, 2010, 4: $300-304$

44 Costa E V L, Nogueira R A. Multifractal dimension and lacunarity of yolk sac vasculature after exposure to magnetic field. Microvascular Res, 2015, 99: 1-7

45 Costa E V L, Jimenez G C, Barbosa C T F, et al. Fractal analysis of extra-embryonic vascularization in Japanese quail embryos exposed to extremely low frequency magnetic fields. Bioelectromagnetics, 2013, 34: 114-121

46 Athanasiou A, Karkambounas S, Batistatou A, et al. The effect of pulsed electromagnetic fields on secondary skin wound healing: An experimental study. Bioelectromagnetics, 2007, 28: 362-368

47 Ottani V, De Pasquale V, Govoni P, et al. Effects of pulsed extremely-low-frequency magnetic fields on skin wounds in the rat. Bioelectromagnetics, 1988, 9: 53-62

48 Yuan Y, Wei L, Li F, et al. Pulsed magnetic field induces angiogenesis and improves cardiac function of surgically induced infarcted myocardium in Sprague-Dawley rats. Cardiology, 2010, 117: 57-63

49 Xue J W, He Y X, Liu Y C, et al. Magnetic field intervention on blood vessel distribution in scar after sciatic nerve injury in rats (in Chinese). Med Res Educ, 2018, 35: 19-23 [薛金伟, 何艳霞, 刘亚纯, 等. 磁场对大鼠坐骨神经损伤后痈痕处血管分布的影响. 医学研究与教育, 2018, 35: 19-23] 
50 Grace K L, Revell W J, Brookes M. The effects of pulsed electromagnetism on fresh fracture healing: osteochondral repair in the rat femoral groove. Orthopedics, 1998, 21: 297-302

51 Callaghan M J, Chang E I, Seiser N, et al. Pulsed electromagnetic fields accelerate normal and diabetic wound healing by increasing endogenous FGF-2 release. Plast Reconstr Surg, 2008, 121: 130-141

52 Roland D, Ferder M, Kothuru R, et al. Effects of pulsed magnetic energy on a microsurgically transferred vessel. Plast Reconstr Surg, 2000, 105: 1371-1374

53 Weber R V, Navarro A, Wu J K, et al. Pulsed magnetic fields applied to a transferred arterial loop support the rat groin composite flap. Plast Reconstr Surg, 2004, 114: 1185-1189

54 Balanezhad S Z, Parivar K, Baharara J, et al. The synergistic effects of sodium valproate and extremely low frequency electromagnetic field on angiogenesis. Sci Res Essays, 2011, 6: 1-5

55 Mousavi M, Baharara J, Shahrokhabadi K. The synergic effects of Crocus sativus L. and low frequency electromagnetic field on VEGFR2 gene expression in human breast cancer cells. Avicenna J Med Biotechnol, 2014, 6: 123

56 Ji B M, Song G L, Zhang X Y. The hemoprotective effects of a rotary magnetic field in mice exposed to $\gamma$ irradiation (in Chinese). Chin J Phys Med Rehabil, 2006, 28: 446-449 [季百苗, 宋国丽, 张小云. 旋转磁场对放射损伤小鼠造血保护作用的研究. 中华物理医学与康复杂志, 2006, 28: 446-449]

57 Wang J, Xiang B, Deng J, et al. Externally applied static magnetic field enhances cardiac retention and functional benefit of magnetically ironlabeled adipose-derived stem cells in infarcted hearts. Stem Cells Transl Med, 2016, 5: 1380-1393

58 Yun H M, Ahn S J, Park K R, et al. Magnetic nanocomposite scaffolds combined with static magnetic field in the stimulation of osteoblastic differentiation and bone formation. Biomaterials, 2016, 85: 88-98

59 Hao S, Meng J, Zhang Y, et al. Macrophage phenotypic mechanomodulation of enhancing bone regeneration by superparamagnetic scaffold upon magnetization. Biomaterials, 2017, 140: 16-25

60 Zhang B-f, Jiang H, Chen J, et al. Silica-coated magnetic nanoparticles labeled endothelial progenitor cells alleviate ischemic myocardial injury and improve long-term cardiac function with magnetic field guidance in rats with myocardial infarction. J Cell Physiol, 2019, 234: 18544-18559

61 Rieck S, Heun Y, Heidsieck A, et al. Local anti-angiogenic therapy by magnet-assisted downregulation of SHP2 phosphatase. J Control Release, 2019, 305: 155-164

62 Xie J, Yan C, Yan Y, et al. Multi-modal Mn-Zn ferrite nanocrystals for magnetically-induced cancer targeted hyperthermia: A comparison of passive and active targeting effects. Nanoscale, 2016, 8: 16902-16915

63 Liang Y J, Yu H, Feng G, et al. High-performance poly(lactic-co-glycolic acid)-magnetic microspheres prepared by rotating membrane emulsification for transcatheter arterial embolization and magnetic ablation in $\mathrm{VX}_{2}$ liver tumors. ACS Appl Mater Interfaces, 2017, 9: 43478-43489

64 Luo C, Yang X, Li M, et al. A novel strategy for in vivo angiogenesis and osteogenesis: Magnetic micro-movement in a bone scaffold. Artif Cell Nanomed B, 2018, 46: 636-645

65 Chen T, Xie X L, Wang C X, et al. Orthogonal test design for the optimization of superparamagnetic chitosan plasmid gelatin microspheres that promote vascularization of artificial bone. J Biomed Mater Res Part B: Appl Biomater, 2019, doi: 43110.1002/jbm.b.34491

66 Dandamudi S, Patil V, Fowle W, et al. External magnet improves antitumor effect of vinblastine and the suppression of metastasis. Cancer Sci, 2009, 100: 1537-1543

67 Song G L, Ji B M, Zhang X Y. Effect of rotating and stationary magnetic field on mice receiving 5-fluorouracil (in Chinese). Chin J Rehabil Theory Practice, 2006, 12: 213-216 [宋国丽, 季百苗, 张小云. 旋转恒定磁场对化疗损伤小鼠造血功能保护作用的研究. 中国康复理论与实践, 2006, 12: $213-216]$

68 Song M, Kim Y J, Kim Y H, et al. Long-term effects of magnetically targeted ferumoxide-labeled human neural stem cells in focal cerebral ischemia. Cell Transplant, 2015, 24: 183-190

69 Vosen S, Rieck S, Heidsieck A, et al. Improvement of vascular function by magnetic nanoparticle-assisted circumferential gene transfer into the native endothelium. J Control Release, 2016, 241: 164-173

70 Carmeliet P. Mechanisms of angiogenesis and arteriogenesis. Nat Med, 2000, 6: 389-395

71 Carmeliet P, Jain R K. Angiogenesis in cancer and other diseases. Nature, 2000, 407: 249-257

72 Li F, Yuan Y, Guo Y, et al. Pulsed magnetic field accelerate proliferation and migration of cardiac microvascular endothelial cells. Bioelectromagnetics, 2015, 36: 1-9

73 Wang Y M, Jin S J, Lu Y Z, et al. Study of effect of magnetic fields on human umbilical vein endothelial cells (in Chinese). Chin J Phys Med Rehabil, 2007, 29: 522-524 [王益民, 靳世久, 陆一竹, 等. 永磁磁场对内皮细胞的影响及其量效关系研究. 中华物理医学与康复杂志, 2007, 29: 522-524]

74 Li F, Jia G L, Zhang R Q, et al. The effects of static magnetic field on the proliferation of human umbilical vein endothelial cells (in Chinese). Chin J Phys Med Rehabil, 2003, 25: 133-135 [李飞, 贾国良, 张荣庆, 等. 恒磁场对人脐静脉内皮细胞增殖的影响. 中华物理医学与康复杂志, 2003, 
25: 133-135]

75 Zhang R Q, Li F, Jia G L, et al. The effects constant magnetic field on the proliferation of rabbit aorta endothelial cells (in Chinese). Chin Heart J, 2002, 14: 480-481, 484 [张荣庆, 李飞, 贾国良, 等. 恒磁场对兔主动脉内皮细胞增殖的影响. 心脏杂志, 2002, 14: 480-481, 484]

76 Ma B, Cheng H X, Zhou L, et al. Effect of constant magnetic field of different intensity on proliferation of endothelial cells in rat aorta (in Chinese). Chin J Clin Rehabil, 2004, 8: 1048-1049 [马波, 程何祥, 周廉, 等. 不同强度恒磁场对大鼠主动脉内皮细胞增殖的影响. 中国临床康复, 2004, 8: 1048-1049]

77 Li F, Xu K, Wang H, et al. Effects of static magnetic field on human umbilical vessel endothelial cell. J Med Coll PLA, 2007, 22: 106-110

78 Li F, Wang H C, Guo W Y, et al. Biologic effects of static magnetic field on proliferation and ultra-microstructure of human umbilical vascular endothelial cell (in Chinese). Chin J Arterioscler, 2006, 14: 140-142 [李飞, 王海昌, 郭文怡, 等. 恒磁场对人脐静脉内皮细胞活性及超微结构的 影响. 中国动脉硬化杂志, 2006, 14: 140-142]

79 Polidori E, Zeppa S, Potenza L, et al. Gene expression profile in cultured human umbilical vein endothelial cells exposed to a $300 \mathrm{mT}$ static magnetic field. Bioelectromagnetics, 2012, 33: 65-74

80 Hu T, Jia G L, Lü A L, et al. The adjusting effect of static magnetic field on the proliferation of human umbilical vein endothelial cells (in Chinese). Chin J Clin Rehabil, 2003, 7: 1376-1377 [胡涛, 贾国良, 吕安林, 等. 恒磁场对人脐静脉内皮细胞增殖的影响实验证据支持磁场效应可降低 RS发生率. 中国临床康复, 2003, 7: 1376-1377]

81 Cheng H X, Zhou L, Zhang R Q, et al. Effects of constant magnetic field on proliferation and apoptosis of human umbilical vein endothelial cells intervened by angiotensin II (in Chinese). Chin J Phys Med Rehabil, 2005, 27: 32-35 [程何祥, 周廉, 张荣庆, 等. 恒磁场对血管紧张素 II 作用下 人脐静脉内皮细胞增殖与调亡的影响. 中华物理医学与康复杂志, 2005, 27: 32-35]

82 Cheng H X, Zhang R Q, Wang H C, et al. Effects of constant magnetic field on proliferation and apoptosis of human umbilical vein endothelial cells intervened by hydrogen peroxide (in Chinese). Chin J Gerontol, 2004, 24: 623-525 [程何祥, 张荣庆, 王海昌, 等. 恒磁场对过氧化氢作用下 人脐静脉内皮细胞增殖与调亡的影响. 中国老年学杂志, 2004, 24: 623-525]

83 Li F, Jia G L, Zhang R Q, et al. Effects of weak static magnetic field on the proliferation of human umbilical vein and rabbit aorta endothelial cells (in Chinese). Chin J Pathophysiol, 2003, 19: 772-777 [李飞, 贾国良, 张荣庆, 等. 弱恒磁场对人脐静脉及免主动脉内皮细胞增殖的影响. 中国 病理生理杂志, 2003, 19: 772-777]

84 Martino C F, Perea H, Hopfner U, et al. Effects of weak static magnetic fields on endothelial cells. Bioelectromagnetics, 2010, 31: 296-301

$85 \mathrm{Hu} \mathrm{T}$, Lü A L, Jia G L, et al. Effect of low frequency electromagnetic field on proliferation of endothelial cells in human umbilical vein (in Chinese). Chin J Phys Ther, 2001, 24: 328-330 [胡涛, 吕安林, 贾国良, 等. 低频电磁场对人脐静脉内皮细胞增殖的影响. 中华理疗杂志, 2001, 24: 328-330]

86 Hu T, Lü A L, Cao Y J, et al. Effect of low frequency electromagnetic field on the cell cycle progression of human umbilical vein endothelial cells (in Chinese). J Clin Cardiol (China), 2002, 18: 27-29 [胡涛, 吕安林, 曹燕杰, 等. 低频电磁场对人脐静脉内皮细胞周期的影响. 临床心血管病 杂志, 2002, 18: 27-29]

87 Liu N, Li F, Wang H C, et al. Effects of triangular low-frequency pulsed magnetic fields on proliferation, migration and cell cycle of cardiac microvascular endothelial cells (in Chinese). Chin Heart J, 2011, 23: 73-76 [刘楠, 李飞, 王海昌, 等. 三角波形低频脉冲磁场对大鼠心肌微血管 内皮细胞增殖、迁移和细胞周期的影响. 心脏杂志, 2011, 23: 73-76]

88 Luo H Y, Zheng Z F. Effects of low frequency pulsed magnetic fields on proliferation of cardiac microvascular endothelial cells and connexin43 expression (in Chinese). Chin J Gerontol, 2013, 33: 5673-5675 [罗海燕, 郑昭芬. 低频脉冲磁场对大鼠心肌微血管内皮细胞增殖和缝隙连接蛋 白43表达的影响. 中国老年学杂志, 2013, 33: 5673-5675]

89 Zhang K, Wang H C, Yuan Y, et al. Effects of low frequency pulsed magnetic fields on proliferation of cardiac microvascular endothelial cells and connexin43 expression (in Chinese). Prog Mod Biomed, 2013, 13: 2206-2209, 2282 [张凯, 王海昌, 苑媛, 等. 低频脉冲磁场对大鼠心肌微血管 内皮细胞增殖和缝隙连接蛋白43表达的影响. 现代生物医学进展, 2013, 13: 2206-2209, 2282]

90 Goto T, Fujioka M, Ishida M, et al. Noninvasive up-regulation of angiopoietin-2 and fibroblast growth factor-2 in bone marrow by pulsed electromagnetic field therapy. J Orthopaedic Sci, 2010, 15: 661-665

91 Bekhite M M, Finkensieper A, Abou-Zaid F A, et al. Static electromagnetic fields induce vasculogenesis and chondro-osteogenesis of mouse embryonic stem cells by reactive oxygen species-mediated up-regulation of vascular endothelial growth factor. Stem Cells Dev, 2010, 19: 731-743

92 Dini L, Abbro L. Bioeffects of moderate-intensity static magnetic fields on cell cultures. Micron, 2005, 36: 195-217

93 Li Y, Song L Q, Chen M Q, et al. Low strength static magnetic field inhibits the proliferation, migration, and adhesion of human vascular smooth muscle cells in a restenosis model through mediating integrins $\beta 1-F A K, \mathrm{Ca}^{2+}$ signaling pathway. Ann Biomed Eng, 2012, 40: 2611-2618

94 Markov M S. Angiogenesis, magnetic fields and 'window effects'. Cardiology, 2010, 117: 54-56

95 Chung A S, Lee J, Ferrara N. Targeting the tumour vasculature: Insights from physiological angiogenesis. Nat Rev Cancer, 2010, 10: 505-514

96 Jain R K. Normalization of tumor vasculature: An emerging concept in antiangiogenic therapy. Science, 2005, 307: 58-62 


\title{
Magnetic fields and angiogenesis
}

\author{
Yiming $\mathrm{Zhu}_{1,2 *}^{1,2 \dagger}$, Yanwen Fang ${ }^{3 \dagger}$, Jiancheng Yang ${ }^{4,5}$, Xinmiao $\mathrm{Ji}^{2}$, Zhicai Fang ${ }^{3}$, Peng Shang ${ }^{4 *}$ \& \\ Xin Zhang ${ }^{1,2 *}$ \\ ${ }^{1}$ Institute of Physical Science and Information Technology, Anhui University, Hefei 230601, China; \\ ${ }^{2}$ High Magnetic Field Laboratory, Hefei Institutes of Physical Science, Chinese Academy of Sciences, Hefei 230031, China; \\ ${ }^{3}$ Heye Health Technology Co., Ltd., Huzhou 313300, China; \\ ${ }^{4}$ Research \& Development Institute of Northwestern Polytechnical University in Shenzhen, Shenzhen 518057, China; \\ ${ }^{5}$ Department of Spine Surgery, People's Hospital of Longhua, Affiliated Hospital of Southern Medical University, Shenzhen 518109, China \\ $\dagger$ These authors equally contributed to this work \\ * Corresponding authors, E-mail: shangpeng@nwpu.edu.cn; xinzhang@hmfl.ac.cn
}

This review belongs to a special issue on magnetic surgery (using magnetic field in surgery), which has developed rapidly in the last few years and showed a great potential to be applied in numerous areas. While magnetic surgery has multiple advantages in surgical processes, including but not limited to shorten surgical procedure and duration, reduce inflammation and bleeding, it also adds another exposure source of relatively strong magnetic field to the human bodies. Consequently, concerns were raised regarding the potential adverse effects of these magnets on our bodies. Moreover, people have increased opportunities to be exposed to various magnetic fields generated by magnetic resonance imaging in hospitals, household magnets, cell phones and power lines, therefore, it is essential to investigate the effects of magnetic fields on human bodies.

This review focuses on the effects of magnetic fields on the growth of blood vessels, a process known as angiogenesis. Angiogenesis is involved in a variety of physiological and pathological processes including organ growth and repair, and therefore plays important roles not only in surgical related processes, such as postoperative recovery, but also in other processes such as development and tumor growth. Angiogenesis is regulated by a balance between pro- and antiangiogenic signals, which is frequently altered in various malignant, inflammatory, ischemic, infectious, and immune disorders. Many studies have investigated the influence of magnetic field on angiogenesis in the last few decades. Here in this review, we summarize, analyze and compare magnetic field parameters, such as strength, gradient and frequency, experimental procedures, biological samples examined and the detailed experimental results. Although there is still no consensus on the effects at cellular level, which is largely caused by a lack of systematic research on different magnetic field parameters, it is interesting that we found the angiogenesis of tumor tissues can be inhibited by both static and dynamic magnetic fields at animal level. In contrast, long-term or high-intensity static magnetic field treatment of nontumor tissue seems to be able to promote angiogenesis at animal level. Since the experimental evidences are still inadequate, more systematic investigations are needed to further examine this correlation in the future.

We also discuss the effect of magnetic field combined with chemotherapy and other treatment methods on angiogenesis and summarize the potential mechanisms of magnetic field on angiogenesis. It has been shown that static magnetic fields can affect multiple aspects of the cell, such as gene expression, cell proliferation, antioxidant defense system, as well as calcium levels. People speculate that magnetic field may regulate angiogenesis by affecting multiple signal transduction pathways including the calcium signaling pathway. Meanwhile there are also studies showing that other molecules could be involved in this process, including ROS (reactive oxygen species, ROS), ERK and membrane-bound receptors. Moreover, the mechanism of the differential effects of magnetic fields on angiogenesis in tumor tissue and non-tumor tissue are still not clear. Although physiological and pathological angiogenesis share many commonalities, there are also multiple different regulation pathways between angiogenesis of tumor vs. non-tumor tissues, such as the dependency of VEGF. Indepth investigations are warranted to better understand the effects and underlying mechanisms of varying magnetic fields with different parameters on angiogenesis in normal and pathological conditions.

This review will not only help people to further understand the biological effects of magnetic fields, provide experimental basis for the safe application of magnetic surgery technology, but also lay a foundation for other potential medical applications of magnetic fields in the future.

\section{static magnetic field, dynamic magnetic field, angiogenesis, magnetic field intensity, tumor}

